\title{
Digital Restoration of Maxillary Central Incisors After Trauma Using an Intraoral Scanner and a CAD/CAM System in an 11-year-Old
}

ISSN: 2637-7764

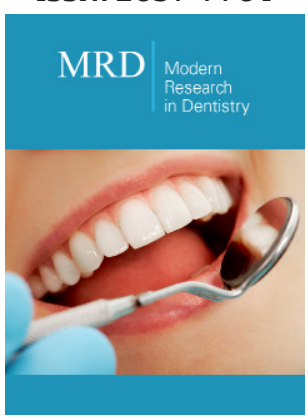

*Corresponding author: Sigalit Blumer, Head, Department of Pediatric Dentistry, Tel Aviv University, School of Dental Medicine, Tel Aviv 69978, Israel

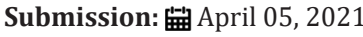

Published: 制April 16, 2021

Volume 6 - Issue 2

How to cite this article: Sigalit Blumer Digital Restoration of Maxillary Central Incisors After Trauma Using an Intraoral Scanner and a CAD/CAM System in an 11-year-Old. Mod Res Dent. 6(2). MRD. 000633. 2021.

DOI: 10.31031/MRD.2021.06.000633

Copyright@ Sigalit Blumer, This article is distributed under the terms of the Creative Commons Attribution 4.0 International License, which permits unrestricted use and redistribution provided that the original author and source are credited.

\section{Sigalit Blumer*}

Head, Department of Pediatric Dentistry, Tel Aviv University, School of Dental Medicine, Tel Aviv 69978, Israel

\begin{abstract}
Background: Most dental trauma in children and adolescents involve anterior tooth fractures. Advancements in ceramics technology and in computer-aided design/computer-aided manufacturing (CAD/CAM) systems, have led to the technological abilities to produce single all-ceramic crowns with high biocompatibility, esthetics, and optimal mechanical properties. However, there is no information regarding the use of this technique in children.
\end{abstract}

Case report: Treatment of extensive crown fractures on an 11-year-old patient using a chairside CAD/ CAM technology. The teeth were scanned, and the restorations were fabricated using the manufacturing unit of the CAD/CAM system and glazed to the appropriate tooth color. At a follow up visits, the restorations kept their strength and esthetic appearance (one year follow up).

Conclusion: The digital restoration treatment is especially suitable for treating children with dental trauma. It has the advantage of better esthetic, functional and durable results compering to conventional restorations, and it often requires only a single session.

Keywords: CAD/CAM; Pediatric Dentistry; Dental Materials; Digital Dentistry; Operative Dentistry

\section{Clinical Significance Statement}

At this case report we describe a digital restoration of young permanent teeth after dental trauma using a CAD/CAM system.

The restoration process is non-traumatic to the patient and can usually be done in a single session. It is a new and improved way of treating extended dental trauma in children and adolescents involving anterior tooth fractures.

\section{Introduction}

Most dental trauma in children involve anterior crown fractures [1], which may cause emotional trauma [2]. Treatment includes composite restorations which are esthetic and easy to repair but may fracture due to their high fragility [3] or suffer from discoloration, poor durability, gingival inflammation and bacterial leakage [4].

Advancements in dental materials and in CAD/CAM systems, have led to the ability of producing single all-ceramic crowns with high biocompatibility, esthetics, and optimal mechanical properties [5].

\section{Case Report}

A healthy 11-year-old male patient arrived the clinic complaining of pain on tooth no.12. Two months earlier he fell and was treated by a dentist.

Tooth no.11 was endodontically treated and both teeth were restored. Intra-oral and radiographic examination revealed an extensive crown fractures of the teeth, involving enamel and dentin. Both restorations had fallen causing pulp irritation and pain on tooth no.12, and exposed gutta-percha on tooth no.11 (Figure 1). 


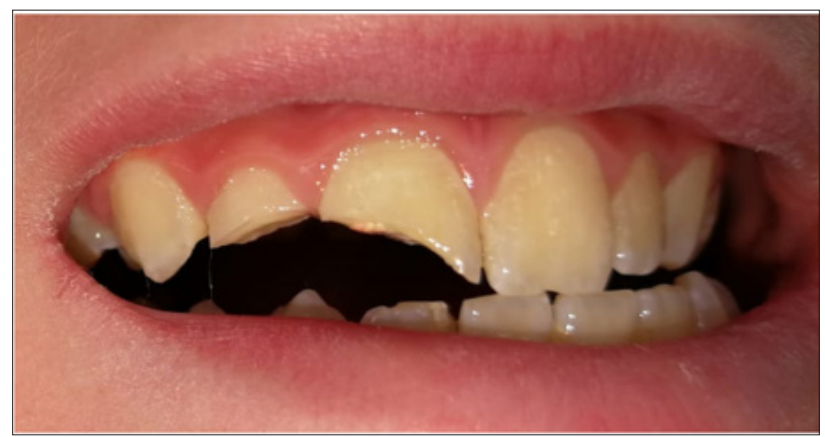

Figure 1: The patient on arrival day. Extensive crown fractures due to trauma, and exposed guttapercha on tooth no. 11 .

An emergency treatment was given: the teeth were cleaned using chlorhexidine, and tooth no.12 was indirectly capped using Vitrebond $^{\mathrm{TM}}$ (3M, Saint Paul, MI, USA).

Three days later, the patient had returned with a complaint of spontaneous pain. A root canal was performed in tooth no.12 and a root canal retreatment was performed in tooth no.11. (Figure 2). The teeth crowns were sealed using glass ionomer (GC Fuji II®, GC Corporation, Tokyo, Japan).

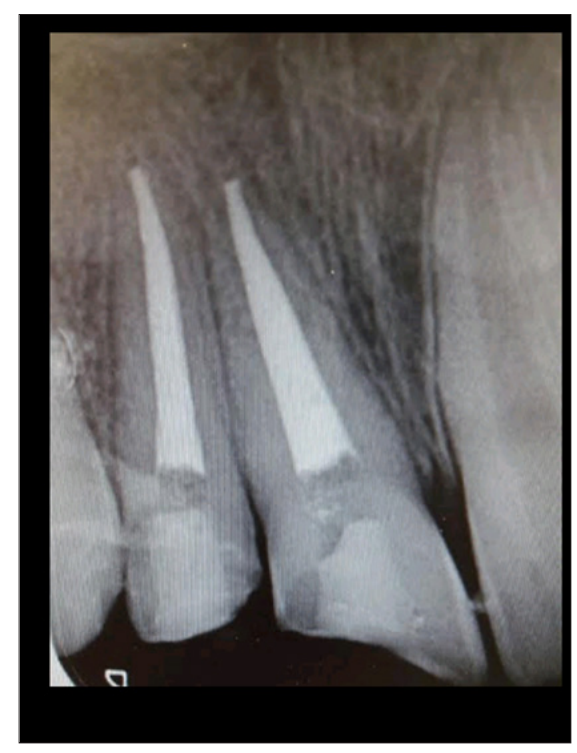

Figure 2: A periapical x-ray after a root canal was performed in tooth no.12 and a root canal retreatment was performed in tooth no. 11 .

Preparation for restoration were made. Tooth no.12: a 3-dimentional Glass Fiber Post (RelyX $\mathrm{X}^{\mathrm{TM}}, 3 \mathrm{M}$ ) was prepared and attached by RelyX ${ }^{\mathrm{TM}}$ Ultimate Adhesive Resin Cement (3M). The buildup core was prepared using Dentsply Core \& Post System (Dentsply Sirona, Benshaim, Germany). Tooth no.11 had sufficient tooth material.

The teeth were prepared with supra-gingival light chamfered finish line $(0.5 \mathrm{~mm})$ providing an adequate thickness for the restoration material. Due to bleeding in the chamfered area, a 3-0 retraction cord (Ultrapak, Ultradent Products Inc., South Jordan, UT, USA) coated with aluminum chloride was used.
The mandible and maxilla were scanned with the Omnicam intraoral scanner (Figure 3) (Dentsply Sirona). Restorations were planned to use the CEREC software version 4.6.3 (Dentsply Sirona). A CERASMART 270 restoration block color HT A2 (GC Corporation) was chosen. The restorations were fabricated using the milling unit, CEREC MC XL (Dentsply Sirona), and coated using light cured OPTIGLAZE ${ }^{\mathrm{TM}}$ (GC Corporation).

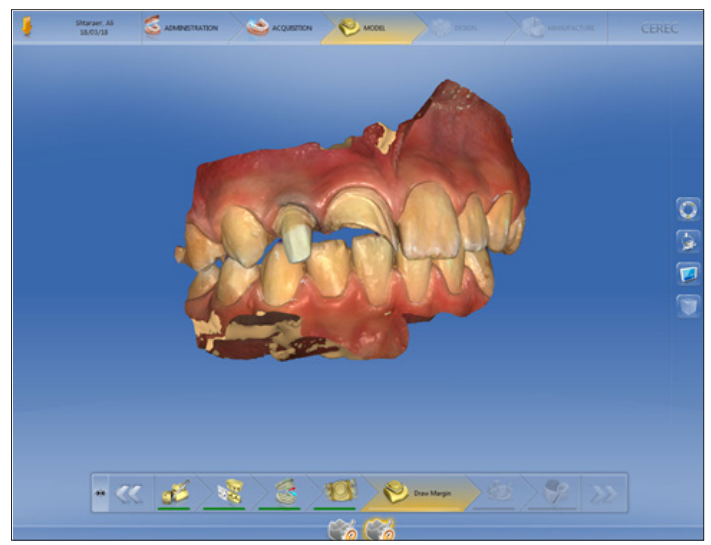

Figure 3: An Omnicam intraoral scanner view of the mandible and maxilla.

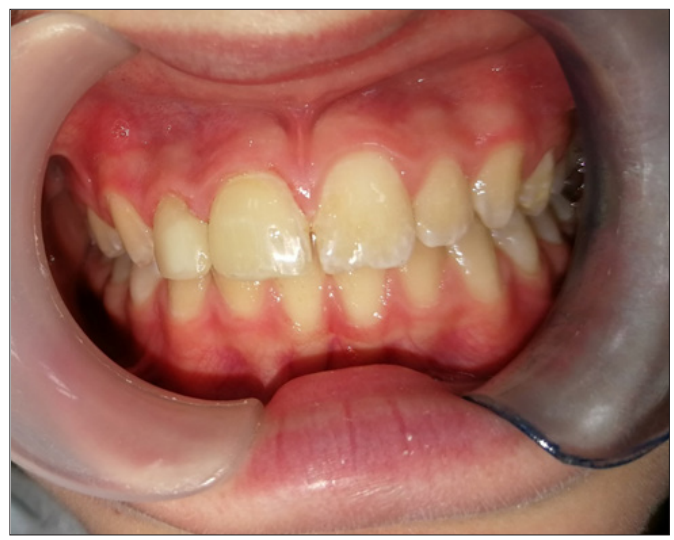

Figure 4: A front view after full restoration.

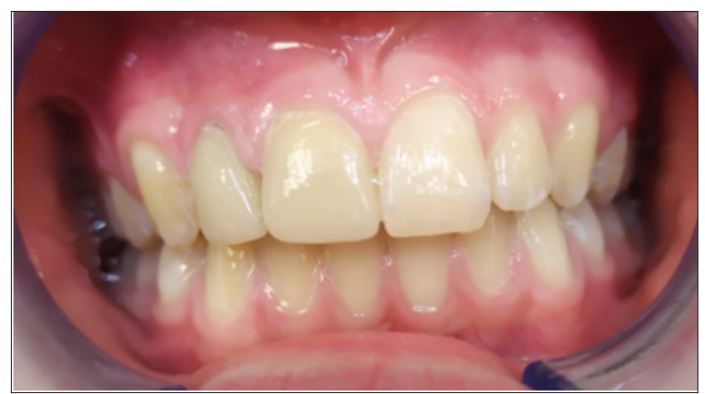

Figure 5: One year follow up.

The teeth were etched using a $35 \%$ phosphoric acid solution (Ultra-Etch $^{\mathrm{TM}}$, Ultradent) and coated with $3 \mathrm{M}^{\mathrm{TM}}$ Single Bond Universal Adhesive. The crowns were then bonded to the teeth using RelyX ${ }^{\mathrm{TM}}$ Ultimate Adhesive Resin Cement (3M) and cured. The crowns were polished and occlusal balance was performed (Figure 4). A mouth guard was prepared in order to prevent future dental 
trauma. At the follow up after one year, the restorations were firm and presented an esthetic outcome (Figure 5).

\section{Discussion}

Restorations using resin composites after dental trauma in children can result in problems such as polymerization shrinkage, discoloration, and wear. To counteract these problems, restoration composites comprising an evenly distributed highly flexible nanoceramic matrix in a barium-containing resin for X-ray radiopacity have been developed (CERASMART 270, GC. This type of composite has high strength after bonding-withstanding up to $270 \mathrm{MPa}$ ultimate tensile strength-as well as high marginal integrity and excellent color durability even after polishing. After scanning the patient's teeth, the restoration is fabricated using the milling unit of the CAD/CAM followed by glazing to the appropriate tooth color.

All of the restoration processes are done at the clinic in a single session reducing the cost of an external laboratory. The patient can participate in designing the restoration. This is especially suitable for treating children. It requires a minimal number of sessions to achieve esthetic, functional and durable results.

\section{Conclusion}

The CAD/CAM system allows optimal planning of treatment, including designing the perfect occlusion, predicting the esthetic result, tooth preparation, fabrication of restorations, and bonding. Moreover, in case the restoration lost or damage, it can be easily fabricated again.

\section{References}

1. Bakland LK, Andreasen JO (2004) Dental traumatology: Essential diagnosis and treatment planning. Endodontic Topics 7(1): 14-34.

2. Rodd H, Noble F (2019) Psychosocial impacts relating to dental injuries in childhood: The bigger picture. Dent J (Basel) 7(1): 23.

3. Walia T, Salami AA, Bashiri R, Hamoodi OM, Rashid F (2014) A randomised controlled trial of three esthetic full-coronal restorations in primary maxillary teeth. Eur J Paediatr Dent 15(2): 113-118.

4. (2018) Textbook and Color Atlas of Traumatic Injuries to the Teeth. In: Jens Andreasen 0, Andreasen FM, Andersson L (Eds.), Wiley-Blackwell, New Jersey, USA.

5. Carlos RB, Thomas Nainan M, Pradhan S, Sharma R, Benjamin S, et al. (2013) Restoration of endodontically treated molars using all ceramic endocrowns. Case Rep Dent 2013: 210763. 